\title{
MULTIPLIER CONVERGENT SERIES
}


This page intentionally left blank 


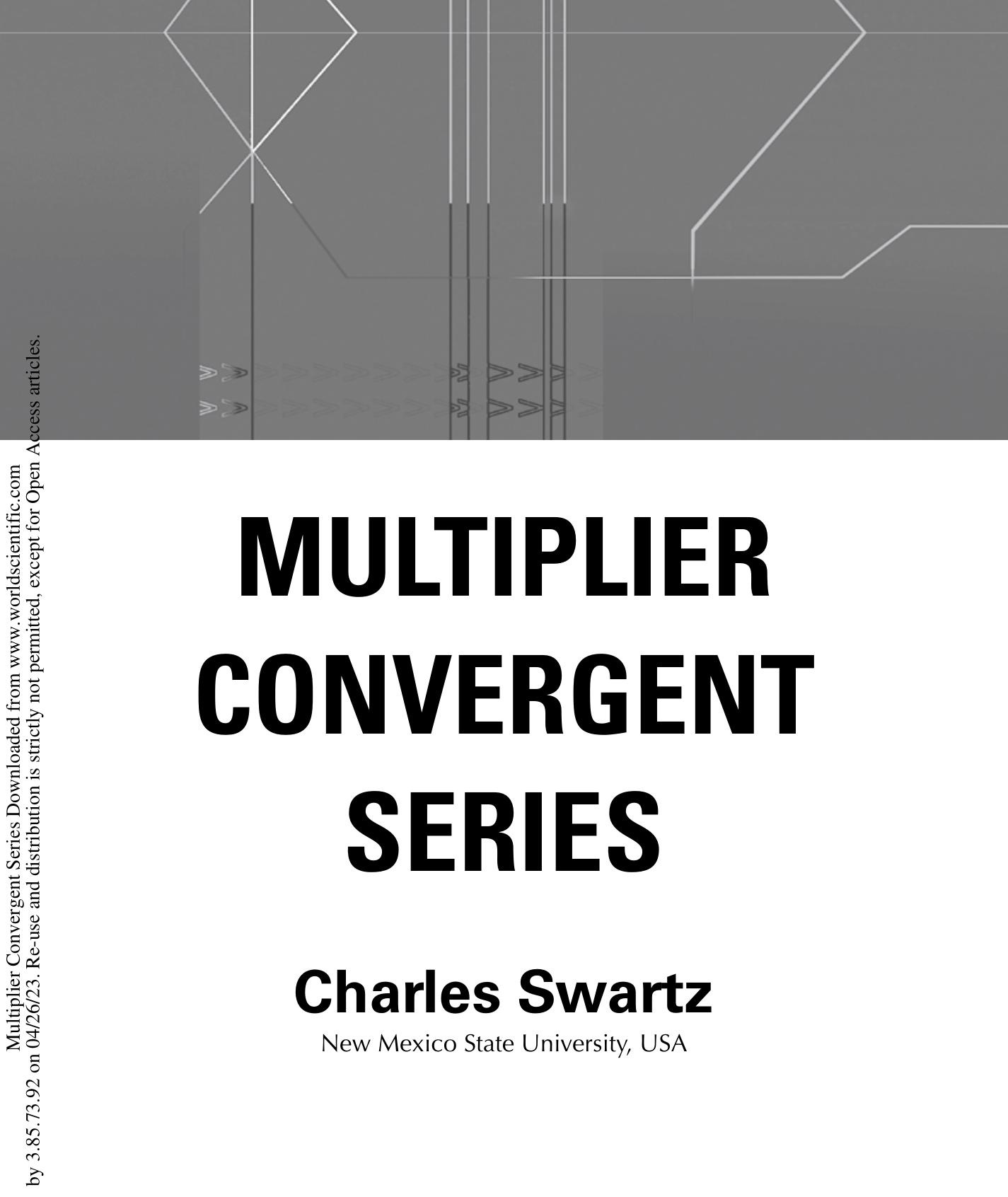


Published by

World Scientific Publishing Co. Pte. Ltd.

5 Toh Tuck Link, Singapore 596224

USA office: 27 Warren Street, Suite 401-402, Hackensack, NJ 07601

UK office: 57 Shelton Street, Covent Garden, London WC2H 9HE

\section{British Library Cataloguing-in-Publication Data}

A catalogue record for this book is available from the British Library.

\section{MULTIPLIER CONVERGENT SERIES}

Copyright (C) 2009 by World Scientific Publishing Co. Pte. Ltd.

All rights reserved. This book, or parts thereof, may not be reproduced in any form or by any means, electronic or mechanical, including photocopying, recording or any information storage and retrieval system now known or to be invented, without written permission from the Publisher.

For photocopying of material in this volume, please pay a copying fee through the Copyright Clearance Center, Inc., 222 Rosewood Drive, Danvers, MA 01923, USA. In this case permission to photocopy is not required from the publisher.

ISBN-13 978-981-283-387-7

ISBN-10 981-283-387-0

Printed in Singapore. 
To the Memory of My Mother 
This page intentionally left blank

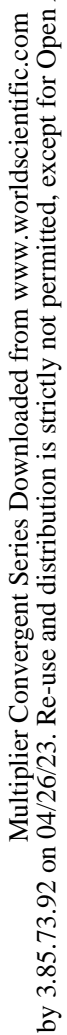




\section{Preface}

This monograph contains an exposition of the properties and applications of multiplier convergent series with values in a topological vector space. If $\lambda$ is a space of scalar valued sequences and $\sum_{j} x_{j}$ is a (formal) series with values in a topological vector space $X$, the series $\sum_{j} x_{j}$ is $\lambda$ multiplier convergent if the series $\sum_{j=1}^{\infty} t_{j} x_{j}$ converge in $X$ for every $\left\{t_{j}\right\} \in \lambda$. For example, if $M_{0}=\left\{\chi_{\sigma}: \sigma \subset \mathbb{N}\right\}$, where $\chi_{\sigma}$ is the characteristic function of $\sigma$, then $M_{0}$ multiplier convergence is just subseries convergence. Basic properties of multiplier convergent series are developed in Chapter 2 and applications of multiplier convergent series to topics in topological vector spaces and vector valued measures are given in Chapter 3. A classical result of Orlicz and Pettis states that if a series in a normed linear space is subseries convergent ( $M_{0}$ multiplier convergent) in the weak topology of the space, then the series is actually subseries convergent $\left(M_{0}\right.$ multiplier convergent) in the norm topology of the space. Generalizations of this theorem to $\lambda$ multiplier convergent series with values in a locally convex space are given in Chapters 4, 5 and 6 . Another classical theorem of Hahn and Schur asserts that if $\sum_{j} t_{i j}$ is absolutely convergent for every $i \in \mathbb{N}$ and if $\lim _{i} \sum_{j \in \sigma} t_{i j}$ exists for every $\sigma \subset \mathbb{N}$ with $t_{j}=\lim _{i} t_{i j}$, then the series $\sum_{j} t_{j}$ is absolutely convergent and

$$
\lim _{i} \sum_{j=1}^{\infty}\left|t_{i j}-t_{j}\right|=0 .
$$

In Chapter 7 we establish generalizations of the Hahn-Schur Theorem to $\lambda$ multiplier convergent series with values in a topological vector space. Chapters 8, 9 and 10 contain applications of the Hahn-Schur Theorems to spaces of multiplier convergent series, double series and automatic continuity of matrix mappings between sequence spaces. 
Chapter 11 extends the notion of multiplier convergent series to series with operator values and multiplier sequences with values in the domains of the operators. Chapters 12 and 13 extend the Orlicz-Pettis Theorem and Hahn-Schur Theorem to operator valued series and vector valued multipliers. Chapter 13 also contains applications to measures with values in a space of continuous linear operators. Chapter 14 considers automatic continuity results for operator valued matrices acting on vector valued sequence spaces. 


\section{Contents}

Preface vii

1. Introduction 1

2. Basic Properties of Multiplier Convergent Series 5

3. Applications of Multiplier Convergent Series 25

4. The Orlicz-Pettis Theorem 49

5. Orlicz-Pettis Theorems for the Strong Topology 83

6. Orlicz-Pettis Theorems for Linear Operators 89

7. The Hahn-Schur Theorem 101

8. Spaces of Multiplier Convergent Series and Multipliers 133

9. The Antosik Interchange Theorem 145

10. Automatic Continuity of Matrix Mappings 157

11. Operator Valued Series and Vector Valued Multipliers 169

12. Orlicz-Pettis Theorems for Operator Valued Series 187 
13. Hahn-Schur Theorems for Operator Valued Series

14. Automatic Continuity for Operator Valued Matrices

Appendix C. Vector Valued Sequence Spaces 